\title{
Economic Growth and Unemployment: A Reappraisal of the Conventional View
}

\author{
JOHN A. TATOM
}

T HE unemployment experience of the 1970s stands in marked contrast to the possibilities for unemployment and growth which had been envisioned by most analysts and policymakers at the end of the 1960 s. At that time, most observers agreed that output could not continue to grow as fast, or the unemployment rate remain as low, as in the late $1960 \mathrm{~s}$ without an accelerating rate of inflation. Nonetheless, maintaining an unemployment rate of about 4 percent and achieving a 4 percent annual growth rate of the nation's output of goods and services appeared to be a realistic expectation. ${ }^{1}$ Except during 1973, however, the unemployment rate has been markedly higher over the past eight years than during the prior decade.

The explanation offered for such apparently excessive unemployment is often quite simple - insuffcient demand for national output. ${ }^{2}$ This view of the unemployment-aggregate demand relationship draws support from an investigation of the link between changes in the unemployment rate and output growth in the $1950 \mathrm{~s}$ and early $1960 \mathrm{~s}^{3}$ The underlying empirical relationship, embodied in what has come to be called "Okun's Law," was originally intended to provide a means of identifying the loss of national output associated with unemployment. While more detailed methods have been developed for this purpose,

\footnotetext{
ISee, for example, Arthur M. Okun, The Political Economy of Prosperity (Washington, D.C.: Brookings Institution, 1970), especially pp. 60 and $100-02$.

2Two of the stronger recent statements of this view may be found in James Tobin, "How Dead is Keynes?" Economic Inquiry (October 1977), pp. 459-68, and Arthur M. Okm, "The Great Stagflation Swamp," Challenge (November/December 1977 ), pp. 6-13.

3Arthur M. Okun, "potential GNP; Its Measurement and Significance," in American Statistical Association, Proceedings of the Business and Economic Statistics Section, 1962, pp. 98-104, and reprinted in The Political Economy of Prosperity pp. 132-45.
}

the simplicity of Okun's Law, as well as its purported success in explaining and forecasting the unemployment rate, has led to its widespread acceptance. ${ }^{4}$

While Okun's Law has provided some insights for analysis of aggregate economic activity, unquestioned acceptance of the original empirical specification of the relationship has been unwarranted. Closer examination indicates that the original specification does not provide an accurate view of the link between changes in the nation's output and unemployment. This relationship between output growth and unemployment can be revised to capture more accurately the empirical link which existed in the 1950s and 1960s, and which continues to hold. Even the revised relationship is shown to provide only a rough explanation of the level of the unemployment rate. Nevertheless, variations in the rate of growth of the nation's output are a sufficiently dominant factor that the revised rule provides a reliable tool for forecasting changes in the unemployment rate. A significant implication of this reappraisal is that judgements concerning economic performance and the role of activist demand management policies based upon the level of, or changes in, the unemployment rate are

4This popularity is illustrated by George L. Perry's remark that "Okun's Law ... is probably the most robust macro. economic relationship yet developed" in "Potential Output: Recent Issues and Present Trends," U.S. Productive Capacity: Estimating The Utilization Gap (St. Louis: Washington University Center for the Study of American Business, 1977), p. 1; and Otto Eckstein's remark in his comment on George L. Perry, "Potential Output and Productivity,"Brookings Papers on Economic Activity (1:1977), pp. 54-55, "It remains as trize today as it was a decade ago that Okun's Law is the best predictor of aggregate unemployment," Also, the tmenployment rate in the St. Louis Model has been determined by an Okun's Law relationship relating the unemployment rate to current and one quarter lagged values of the $G N P$ gap. See Leonall $C$. Andersen and Keith $M$. Carlson, "A Monetarist Model for Economic Stabilization," this Review (April 1970), pp. 9 and 14, and Roger W. Spencer "Population, The Labor Force, and Potential Output: Implications for the St, Louis Model," this Review (Febriary 1971), pp. 15-23. 


\section{Unemployment Rate}

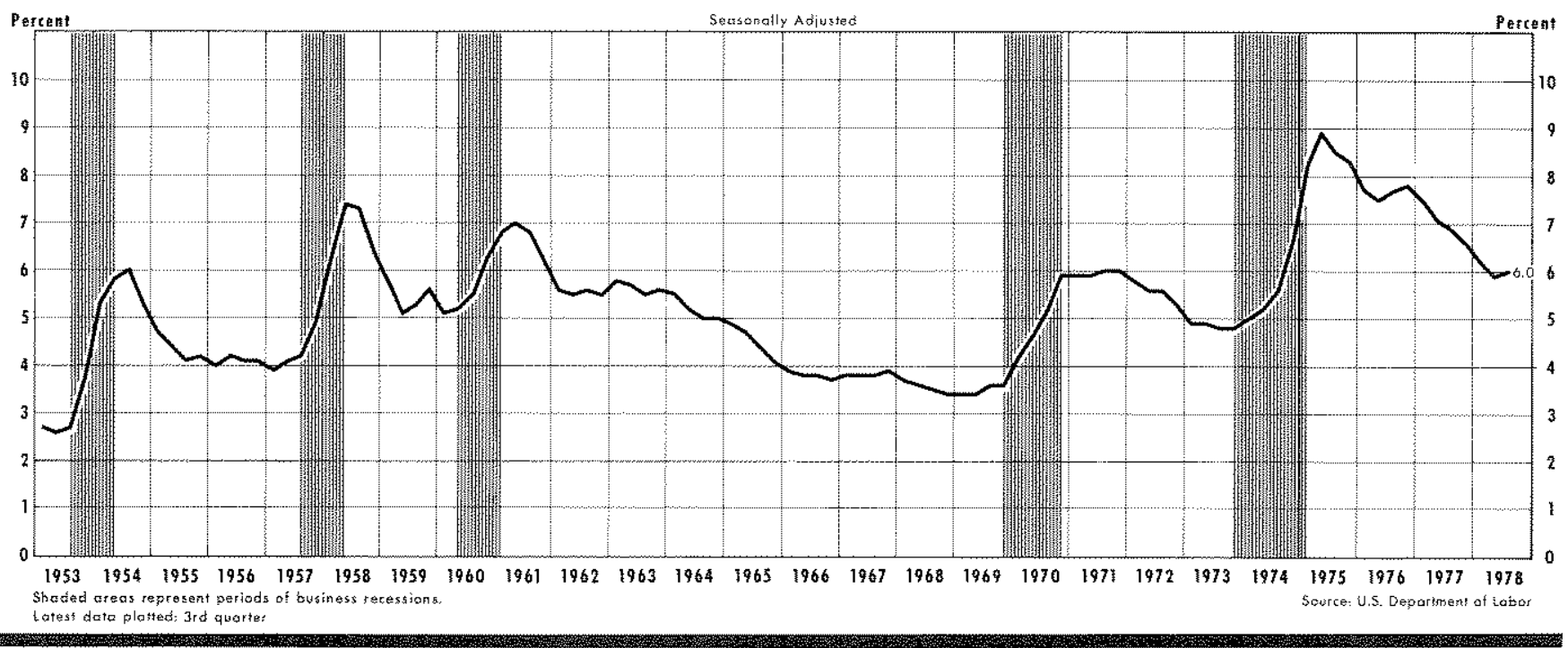

seriously biased by the acceptance of the original specification of Okun's Law.

\section{What Is Okun's Law?}

In his original article, Okun used several statistical techniques to assess the relationship between unemployment and aggregate output in order to establish a measure of the output which could be produced under conditions of "full employment." The techniques used involved relating first differences of unemployment to the growth rate of output, using various measures of the gap between potential and actual output, and using a linear logarithmic relationship between employment and output and time. The benchmark assumption was that full employment and, thus, production at the economy's "potential output" rate, occurred at an unemployment rate of 4 percent. The study concluded that each percentage point of unemployment above 4 percent of the labor force implied a 3 percent "gap" of lost output. 5 This relationship can be summarized as:

$$
\mathrm{U}=4.0+1 / 3 \mathrm{GAP}
$$

where $\mathrm{U}$ is the overall unemployment rate and GAP is the percentage excess of potential over actual output. When the economy's unemployment rate differs from 4 percent, the equation allows a calculation

5Okun, "Potential GNP," p. 100, points out that the 3 to 1 link between output growth and the unemployment rate is approximate. His "own subjectively weighted average of the relevant coefficients" implies a gap coefficient in the equation equal to 0.3125 , slightly lower that the one-third figure used here. of the size of the gap between actual and potential output.

Since Okun's original work, measures of potential output have been developed which take into account additional factors such as the use of capital and energy resources which affect productivity and po-

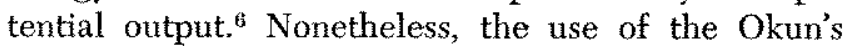
Law relationship as a means of explaining (or at least forecasting) the unemployment rate remains relatively widespread. ${ }^{7}$

Some of the difficulties with the original specification of Okun's Law may be seen by an estimate of equation (I) using quarterly data from I/1953 through III/1977. Two altemative measures of potential output are used to measure the GNP gap; the first, that of the Council of Economic Advisers (CEA), and the second based upon updated quarterly estimates by Rasche and Tatom. ${ }^{8}$

Gee the discussion of the literature on potential output measures in Robert $\mathcal{H}$. Rasche and John A. Tatom, "Energy Resources and Potential GNP," this Review (June 1977), pp. 10-24, especially pp. 10-13.

${ }^{7}$ According to equation (1), changes in the unemployment rate depend upon changes in the gap, which in turn depends on the difference between the rate of change in potential output (economic growth) and the rate of change in actual output. Since the unemployment rate is equally responsive to a decrease in the rate of economic growth or an increase in the rate of change of actual output, the response of the unemployment rate to either is discussed here using the terns economic growth and the rate of change of actual output interchangeably.

"See Peter K. Clark, "A New Estimate of Potential Output," U.S. Congress, Joint Economic Committee, Hearings on the Economic Report of the President, 95th Cong. 1st sess., January 19, 1977, pp. 39-54; and Robert H. Rasche and John A. 
(2)

$$
\begin{aligned}
& \mathrm{U}=4.58+.325 \mathrm{GAP} \quad \text { (CEA measure) } \\
& \mathbf{R}^{2}=.96 \quad \text { S.E. }=.279 \quad \text { D.W. }=1.32 \quad \hat{\rho}=.87 \\
& \text { (3) } \mathrm{U}=4.99+.359 \text { GAP (Rasche-Tatom measure) } \\
& \text { (11.56) (14.35) } \\
& \mathbf{R}^{2}=.97 \quad \text { S.E. }=.250 \quad \text { D.W. }=1.32 \quad \hat{\rho}=.94
\end{aligned}
$$

Both equations indicate constants which are significantly above the 4 percent level used in the original law (t-statistics are shown in parentheses). Moreover, both equations indicate significant serial correlation of the errors, even though allowance is made for a first-order autoregressive scheme. Also, when the rho-statistic is close to unity, the appropriate statistical procedure is estimation of the coefficients using a first-difference form, which in this case would mean that changes in the unemployment rate are related to changes in the GNP gap. ${ }^{9}$

The only change in the original statement of the relationship which has become widely agreed upon is that the unemployment rate at full employment can no longer be regarded as constant at 4 percent. Since different groups of individuals have large differences in their unemployment experience, even under highemployment conditions, changes in the composition of the labor force can have substantial effects on the aggregate unemployment rate. Recent studies of potential output allow for changes in the "full-employment unemployment rate" due to changes in the age and sex composition of the labor force. ${ }^{10}$ Such measures attempt to capture the different unemployment and participation experience of different groups within the labor force. These studies imply the use of a variable intercept, $\mathrm{U}_{\mathrm{f}}$ in equation (1), instead of the constant of 4 percent. The relationship may then be expressed as $U^{*}=b$ GAP, where $\mathrm{U}^{*}$ is the excess of the unemployment rate, $\mathrm{U}$, over the full-employment level, $\mathrm{U}_{t}$, and $\mathrm{b}$ is the responsiveness of the unemployment rate to growth, as measured by changes in the gap. ${ }^{11}$

Tatom, "Potential Output and Its Growth Rate - The Domi" nance of Higher Energy Costs in the $1970^{\circ} \mathrm{s}$, in U.S. Productive Capacity: Estimating the Utilization Gap, pp. 67-106. The minor changes in the latter series reflect data revisions by the Bureau of Labor Statistics and an extension through the third quarter of 1977 . The series used have been subsequently motified, but the conclusions are not appreciably affected by the modifications.

See, for example, Jan Kmenta, Elements of Econometrics (New York: The Macmillan Company, 1971), pp. 289-92.

10See George L. Perry, "Labor Force Structure, Potential Output, and Productivity," Brookings Papers on Economic Activity (3:1971) pp. 533-65; Perry, "Potential Output and Productivity;" Clark, "A New Estimate of Potential GNP;" and Rasche atd Tatom, "Energy Resources and Potential GNP," and "Potential Output and Its Growth Rate."

11Perry, "Labor Force Structure," estimates such an equation using annual data and finds an estimate of $b$ consistent with

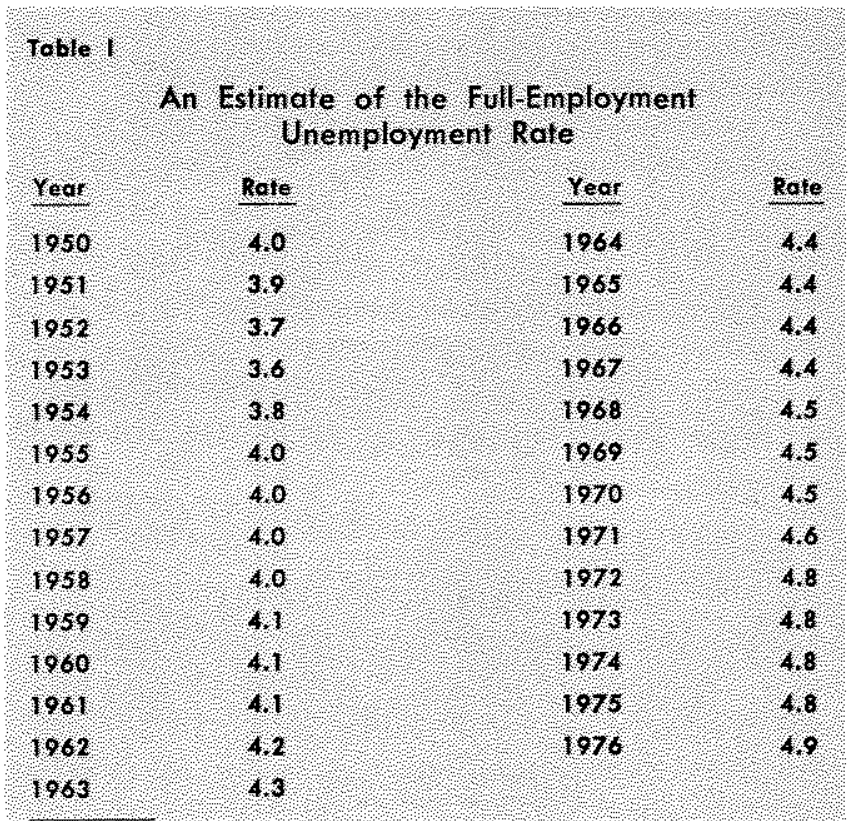

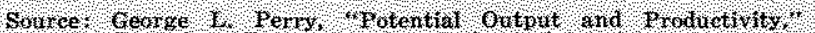
Brookinas Papere on teonomite Aetinty (1 407T) D. 28

For example, Table I shows the annual full-employment unemployment rate recently constructed by Perry. ${ }^{12}$ The measures constructed by the Council of Economic Advisers are quite similar. The estimates indicate that the constant in the Okun's Law equation has risen from 4 percent in 1955 to about 5 percent in the $1970 \mathrm{~s}$. The most noteworthy effect of accounting for the change in the unemployment benchmark is that it indicates the U.S, economy was operating at full employment in 1973 and early 1974, contrary to the dominant view at that time which claimed that the economy had excess capacity. ${ }^{13}$

Okun's original estimate of this responsiveness, When the first-difference test used below is applied to his data, estimates of $b$ are found which are consistent with the larger responsiveness indicated in this article. A fuller discussion of these results is avaitable from the author in the unpublished menorandum, "An Alternative Estimate of Okun's Law."

12See Perry "Potential Output and Productivity," Table 6, p. 28 . Others have suggested increases in the full-employment memployment rate above those estimated by Perry and the CEA. For example, Michael L. Wachter estimates the recent rate is about one-half of one percent above Perry"s estimate. See his comments following Perry, "Potential Output and Productivity," p. 51. Also see Martin Feldstein, "The Econornics of the New Unemployment," The Public Interest (Fall 1973), pp. 3-42, and "Unemployment Compensation: Adverse Incentives and Distributional Anomalies," National Tax Jounal (June 1974), pp. 231-44. Feldstein argues that a more generous unemployment compensation system in the seventies has affected the opportunity cost of accepting employment offers. Such an argument suggests further increases in the benchmark unemployment rate, over and above the increases indicated by demographic factors which are estimated by Perry and the CEA and used below.

${ }^{13}$ See "The Debate Over Ganging the GNP Gap," Business Week, June 9, 1973, pp. 76-77. 
Table 11

Two testmates of $0 \mathrm{~km} \mathrm{~s} \mathrm{law}$ 1/1953 IV/1969\%

\section{Levels}

\section{$\mathrm{G}=$ CEA Output Gap:}

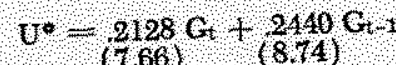

$\mathrm{n}^{2}=97$

$\mathrm{ow}, 1,65$ $\mathrm{s}, \mathrm{s}=4568$

$\mathrm{S} \mathrm{E}_{\mathrm{H}}=196$

$\hat{\rho}=86$

$\mathrm{G}=\mathrm{Rasche}$ Tatom Oitput Qap

$$
\mathrm{U}+(9,75) \mathrm{G}+179 \mathrm{l}) \mathrm{G}
$$

$\mathrm{R}^{2} \geq 9$

$0 . \mathrm{W}=1.40$

$\mathrm{zB}+4575$

$\mathrm{SE} .=196$

$0=86$

1609

\section{First Dilferences}

$\mathrm{G}=$ CEA Output Gap:

$$
\begin{aligned}
& \mathrm{AU}^{*}=2172 \Delta \mathrm{C}_{t}, 2358 \Delta \mathrm{G}_{-} \\
& (7,10)+\text { (8, } 4 \\
& \mathbf{H}^{2}=19 \\
& \mathrm{SH}, 205 \\
& 0 \mathrm{w}=1, \mathrm{~A} \\
& \Sigma P_{1}=453
\end{aligned}
$$

$\mathrm{G}$ - Rasahe-Tatone Qutout Gap.

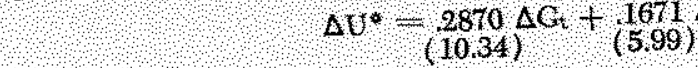

$$
\begin{aligned}
& \mathrm{R}^{2}=.82 \mathrm{DW}=2,00 \quad \mathrm{\Sigma} \beta_{3}=.4542 \\
& \mathrm{~S}, \mathrm{E},=190 \\
& 0=27
\end{aligned}
$$

( $\mathrm{t}$ - statistles are khown in paresheses)

\section{Another Look at Okun's Law}

Estimates of equations of the form $U^{*}=\mathrm{b}$ GAP for the period prior to the 1970s, I/1953-IV/1969, are shown in Table II. The full-employment unemployment rate series used in each case is that prepared by the CEA. ${ }^{14}$ A lagged value of the gap is significant in each case, and there is significant positive autoregression in both of the equations. ${ }^{15}$ Again, the rho-statistic is sufficiently close to unity to indicate

14When constants are included in the equations in Table II they are they are not statistically signim decimal places). This result the gap coefficients (to two dectinal places) int rate series indicates that the full-employment unemployment the rate. used adequately captures the actual changes in the used adequately captures the are also not significant.

A. McNees, "The Current Business Cycle in HistoriFederal Reserve Bank of Boston New Federal Reserve Bank (1978), pp. England Economic Retiew (January/ Fruary 1.aw equa44-59, uses the CEA data to estimate an Okun Law from tion and concludes that it "explains unemploynent from 1973 through 1977 quite well. The equation he uses contans only the current gap. A replication of his equation yelded a value of 0.88 and Durbinm Watson statistic of 1.40 that a first-difference form of the equation is appropriate, and that each equation may suffer from the omission of other significant explanatory variables. First-difference equations are shown in the lower portion of Table II. Note that in the second equation, autoregression is a problem, even in the first-difference form, which has been removed using the CochraneOreut technique. The first difference equation estimates provide strong support for the size of the response of the level of unemployment found in the level equations.

The equations indicate that unemployment is more sensitive to the rate of change of output than the original Okun's Law suggests. ${ }^{16}$ Conversely, this means that the change in the output gap associated with a given change in the unemployment rate is smaller than implied by the original specification. The sum of the coefficients on the current and lagged values of the gap terms indicates a gap coefficient close to 0.45 . The sum coefficient indicates that a 2.22 percent $(1 / 0.45)$ output loss is associated with each one percent of unemployment in excess of the full-employment level.

This change has important implications for the conduct of monetary and fiscal policy. If unemployment is more sensitive to growth than the original formula indicates, the GNP gap associated with any observed level of unemployment would be smaller. Thus, the increase in output required at any time to achieve full employment is smaller than the original relationship indicates. Also, high-employment budget estimates which are based on overly optimistic assess.

in incate the misspeciffcation introm These statisties partly indicate the misspecincation introm duced by omitting a significant lagged value of the gap. In spite of the forecast errors using the equation. On averthe size of the forecast errors using 0.74 percentage points age, the unemployment forecast is 0.14 percentage ponts above the actual rate during 1974 , and 0.75 percentage points below the actual rate observed from

quarter of 1975 through the beginning of 1977 .

$16 \mathrm{~A}$ look back at one of Okum's methods of estimating this lok difference in results. When okun responsiventess reveals the between quarterly changes in the estimated the relationship between quarterly changes omitted unemployment rate and actual output growth, he if it had a significant lagged ontput growth term which, if it had a significant included, would have yielded the results above. For example, when changes in the unemployment rate for the civilian labor force age fourteen and over are used with real GNP growth for the period III/1947-IV/1960, Oktn's rea GN the constant is 0.30 and the output growth coefficient is -0.31 , essentially Okun's results $(-0.30)$ for the period beginning in II/ 1947 . When outpat growth $(-0.21)$ prior quarter is added to the equation, its coemcient $(-0.21)$ is significant $(t=-5.78)$. When added to the current approxigrowth coefficient $(-0.23)$, the sun $(-0.44)$ is approximately the size of the gap coefficient found above. 0.70 , constant in such an equation is 0.42 , while the $\mathrm{R}^{2}$ is 0.70 , D.W. 1.80, S.E. $=0.31$. The standard error s mathedly fower than when only current output growth is included $(0.40)$. 
ments of this output gain provide a mistaken impression of the possibilities for new spending initiatives and tax cuts or understate high-employment Federal borrowing requirements. Finally, attempts to change the unemployment rate through policies which temporarily stimulate or slow output growth would yield larger unemployment rate changes than anticipated. Such policy errors would promote greater cyclical variability of the economy's output.

\section{The Unemployment Rate in the 1970 s}

Dynamic simulations of the unemployment rate level equations in Table II do not forecast the unemployment rate in the 1970 s well using the respective GNP gap estimates. ${ }^{17}$ On the other hand, the evidence in Table II indicates that neither equation should be expected to perform well, since the statistical properties of the equations show the appropriate statistical relationship is the first-difference form. That is, an equation of the form proposed by Okun (augmented for a lagged response) can give reasonable predictions of changes in the unemployment rate, but it does not predict the actual level of the unemploy. ment rate very well. The role of the adjustment for autoregression in obtaining the excellent fit of the level equations during the sample period is very large. Other factors may be of too great importance to allow one to forecast unemployment levels well using only information on output gaps.

Simulations of the first-difference equations forecast much better. ${ }^{18}$ For the forecast period 1/1970III/1977, the average error in predictions of changes in the excess unemployment rate is 0.011 and the root-mean-squared error is 0.23 , using the CEA equa-

\footnotetext{
17The appropriate test of the forecasting ability of the equations are dynamic simulations which omit information on the past forecast errors during the out of -sample period. Static simulations take into account the lagged error term in the equations. The mean error and root-mean-squared error for the CEA level equation for the period $1 / 1970-I I I / 1977$ are -0.22 percent and 0.50 percent, respectively. The mean error of the dynamic simulation of the Rasche Tatom equation of 0.46 percent indicates underprediction and the root-meansquared error is 0.62 percent. Static simulations of the level equations forecast better for the same period, yielding mean errors and root-mean-squared errors of -0.04 and 0.23 percent, respectively, for the CEA equation and 0.06 and 0.17 percent, respectively, for the Rashe-Tatom equation. Thus, static forecasts using either equation may provide fairly accurate one quarter" ahead forecasts while not "explaining" unemployment very well.

18 Since the estimate of the first-difference equation using the Rasche-Tatom gap measures includes the lagged error term to eliminate autocorrelation, the simulation reported is again a dynamic one. The simulation of the equation which uses the CEA gap measure is a static simulation since the estimated equation is an ordinary least squares (OLS) estimake.
}

Table III

\section{Two Estimates of Okun's Law 1/1953-111/1977*}

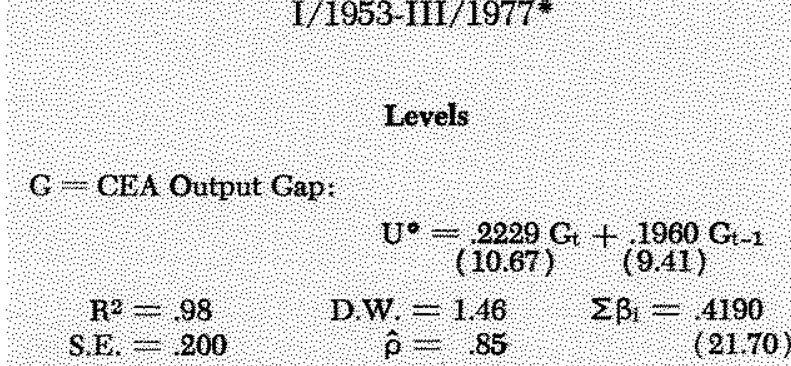

G. - Rasche Taton Output Gap:

$$
\begin{aligned}
& { }^{4} \mathrm{U}=(13.19)+(8.72) \mathrm{G} t_{1} \\
& \mathrm{R}^{2}=98 \quad \text { DW }=1.40 \quad \quad \Sigma B_{t}=4594 \\
& \text { S.E. }=187 \text { Q } \hat{\rho}=05 \text { प }(21.33)
\end{aligned}
$$

First Differences

G = CEA Output Gap:

$$
\begin{aligned}
& \Delta \mathrm{U}^{*}=(11.68) \Delta \mathrm{G}+\frac{1826 .}{(8.84)} \Delta \mathrm{G}_{t_{1}} \\
& \mathrm{R}^{2}=80 \quad \mathrm{DW}=1.94 \quad \Sigma \beta_{1}=.4239 \\
& \text { StE. }=2.02 \\
& \hat{\rho}=24 \\
& \text { (16.38) }
\end{aligned}
$$

$\mathrm{G}+$ rasche-Tatom Ontpit Cap:

$$
\begin{aligned}
& \text { t } \\
& \mathrm{R}^{2}-84 \text { DW } 2005 \quad \Sigma \mathrm{B}_{1}=4548 \\
& \mathrm{SH}=181 \\
& 0=30 \\
& (1801
\end{aligned}
$$

(t statintes are shown in parentheses)

tion in Table II. The comparable errors using the Rasche-Tatom equation are 0.08 and 0.18 , respectively. While the average error in each reflects the inability of the first-difference equations, on average, to explain fully the higher levels of the unemployment rate since the end of the $1960 \mathrm{~s}$, the size of the average error is not significantly different from zero. The rootmean-squared error of the first-difference equation forecasts are only slightly different from the standard error in the sample period.

When the equations in Table II are reestimated through the third quarter of 1977 , there are only slight changes in the equations. These equations are shown in Table III. The fit of the Rasche-Tatom equations is slightly better over the longer period, while that of the CEA equations is slightly worse. Again there is agreement between the gap coeffcients in both the level and first-difference equations. The sum of the coefficients in the Rasche-Tatom 
equations is about the same as in the earlier period while the sum in the CEA equations falls to 0.42 . The Chow test indicates the absence of structural change in the post-1969 period in all cases but one. ${ }^{19}$ Thus, the quality of the level forecasts from the simulations of the equations estimated over the $1950 \mathrm{~s}$ and $1960 \mathrm{~s}$ does not appear to arise from a change in the structure of the empirical relationship.

Okun's Law, even when revised, provides only a very rough explanation of the unemployment rate in the 1970s. While the evidence shows that changes in the gap, due to differential growth rates in potential and actual output, have a significant impact on changes in the unemployment rate from quarter-toquarter, and that this relationship does appear to have remained stable in the $1970 \mathrm{~s}$, it also indicates that the relationship between the GNP gap and the level of the unemployment rate is not sufficient to explain satisfactorily the high levels of unemployment since 1969.

\section{Prospects for the Unemployment Rate}

Using a device like Okun's Law, the prospects for unemployment rate developments may be readily stated. According to the revised "law," the unemployment rate declines roughly 0.45 percentage points per year for each one percent excess of real GNP growth over the rate of growth of potential output.

For example, the Administration recently forecast a rate of real GNP growth for $1978-79$ of 4.75 percent and projected a continuation of this growth through 1983 to achieve their goals. ${ }^{20}$ The accompanying path of the unemployment rate indicates a decline of 0.4 percentage points per year, with the rate reaching 4.9 percent at the end of 1981 and 4.0 percent in IV/1983. While it is not explicitly stated, the estimated reductions appear to be based upon an assumed rate of growth of potential output of 3.5 percent per year together with the old "three to one" link between growth and unemployment given by the original form of Okun's relationship. Such a rate of

\footnotetext{
19The first-diference equation using the CEA output gap measures has a significant antoregressive disturbance term in the longer period which is not significant the the earlier period. A Chow test of structural change using both the ofdinary least squares and generalized least squares estimates of the equation indicates stuctural change at the one percent significance level in the generalized least squares estimate.

20See U.S. Management and Budget Office, The Budget of the United States Goternment: Fiscal Year 1979, pp. 29-33.
}

growth of potential output was discussed by the CEA in $1977 . .^{21}$

The same assumptions about the growth of output ( 4.75 percent) and potential output ( 3.5 percent) give a much larger reduction in the unemployment rate over the next five years, however, when the revised rule is used. The reduction of the unemployment rate to the full-employment benchmark used here, 4.9 percent, would occur in the second quarter of 1980 rather than at the end of 1981 , as in the budget projection. Moreover, the assumption of a 3.5 percent rate of growth of potential output is probably optimistic and thus understates the rate of reduction of the GNP gap. This means that the unemployment rate would fall faster than the Administration estimate. The average annual growth rate of potential output from the recession trough through the third quarter of last year is only 3.0 percent in the Rasche-Tatom estimate, as opposed to the 3.5 percent projection in the CEA data. ${ }^{22}$ If continued, the excess of actual over potential growth would be 1.75 percent per year with the Administration's forecast of GNP growth, resulting in an annual reduction of about 0.8 percentage points in the unemployment rate $(0.45 \times 1.75=0.7875)$, about twice the rate of decline estimated by the Administration. ${ }^{23}$ Should such actual and potential output growth be realized from the second quarter of 1978 on, the fullemployment unemployment rate benchmark used here of 4.9 percent would be achieved in the third quarter of 1979 rather than at the end of 1981 , as projected in the budget. Viewed in terms of timing, recent budget policy proposals aimed at achieving an unemployment target by a certain date in the future appear to be much more stimulative than the proposed budget indicates. ${ }^{24}$

\footnotetext{
See Council of Economic Adyisers, Economic Report of the President, 1977, pp. 55-56.

"See Rasche and Tatom, "Potential Output and Its Growth Rate," pp. 84, 100-102.

23:The contrast may also be seen with reference to data from the recent past. The unemployment rate in the first quarter of 1978 was 6.2 percent, 2.7 percentage points lower than the unemployment rate peak in the second quarter of 1975 . Over this period, real GNP growth averaged 5.0 percent per year. The post recession potential output growth rate of 3.0 percent annually, together with the 0.45 rule, indicates a decline of 2.5 percent over these eleven quarters, only slightly below the reduction in excessive umemployment actually observed. Using the one-third estimate of the responsiveness and 3.5 percent annual potential growth implies a reduction of only 1 , 4 percentage points, much smaller than the reduction which actually occurred.

24See Keth M. Carlson, "Economic Goals for 1981: A Monetary Analysis, "this Review (November 1977), po. $2 m-7$, for an analysis of an earlier Administration plan. He points ont the implications of policies to achieve such rapid real GNP
} 


\section{Summary and Conclusion}

Okun's Law - a relationship between the unemployment rate and the level of the GNP gap - was not originally intended to explain the unemployment rate, but instead, to provide a means for measuring potential output. In recent years, alternative methods have been developed to measure potential output which have a stronger basis in economic theory and statistical method. Nonetheless, use of the relationship as an explanation of the unemployment rate has continued.

An examination of Okun's original formulation as an explanation of unemployment shows that it is not very satisfactory. Besides recent evidence showing that the full-employment unemployment rate has risen since the original work, the evidence presented here points to a larger responsiveness of the unemployment rate to real output growth.

growth for accelerating inflation and negligible real Federal spenditg growth.
When the revised pieces of Okun's Law are reassembled, a serious statistical problem remains. The coefficient of a lagged error term required to eliminate autoregression in the level equations is near unity and plays a major role in the high quality of the statistical results. Forecasts based upon the level equations tend to be of significantly lower quality beyond a sample period since this disturbance term cannot be taken into account.

Nonetheless, the first-difference equations and the simulation experiment indicate strong support for the larger responsiveness found in the level equations and, more importantly, show that quarterly changes in the level of the unemployment rate are dominated by economic growth. Thus, the rule of thumb developed here may be a useful tool for forecasting. This rule, however, indicates that the unemployment rate is more sensitive to economic growth than most observers may have believed and suggests the use of increased caution in attempts to guide the economy by activist demand policies.

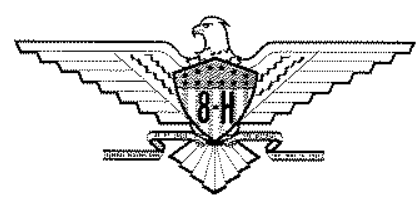

